\title{
Explorando Medidas de Comprimento, Criatividade e Interdisciplinaridade com Minetest no Ensino Fundamental
}

\author{
Márcia Regina Kaminski ${ }^{1}$, Clodis Boscarioli \\ 1,2 Universidade Estadual do Oeste do Paraná \\ Rua Universitária, 2069 - Jardim Universitário, Cascavel, Paraná \\ \{marciarkjf, boscarioli\}@gmail.com
}

\begin{abstract}
The interest of young people in simulation and strategy games has led to discussions about the possible contributions of these games to teaching and learning processes and how they could be inserted into pedagogical practices. This paper describes an experiment with the Minetest game to address the length measurement content with fifth year students of Elementary School. The results point contributions not only to student engagement but also to an interdisciplinary learning and for the integral formation, evidencing, however, the need of an adequate infrastructure so that the full potential of this type of game can be exploited.
\end{abstract}

Resumo. O interesse dos jovens por jogos de simulação e estratégia tem suscitado discussões sobre as possíveis contribuições desses jogos aos processos de ensino e aprendizagem, e sobre como poderiam ser inseridos nas práticas pedagógicas. Este artigo descreve uma experiência com o jogo Minetest para abordar o conteúdo Medidas de Comprimento com estudantes de $5^{\circ}$ ano do Ensino Fundamental. Os resultados apontam contribuições não só na mobilização e engajamento dos estudantes, mas também para uma aprendizagem interdisciplinar e para a formação integral, evidenciando, porém, a necessidade de uma infraestrutura adequada para que se possa explorar todo o potencial desse tipo de jogo.

\section{Introdução}

A integração das Tecnologias Digitais de Informação e Comunicação (TDIC) aos processos de ensino e aprendizagem é discutida já há algum tempo, e suas contribuições são reconhecidas, haja vista que no contexto da realidade cibercultural é inegável que as tecnologias digitais fazem parte do cotidiano dos indivíduos e em especial, das crianças e jovens que frequentam as escolas, uma geração imersa no seu uso. Dessa forma, compreende-se que as tecnologias devem fazer parte dos processos educativos, sendo utilizadas pelos educadores para abordar os conteúdos curriculares, e como parte deles.

O uso de jogos digitais é uma das possibilidades para o trabalho pedagógico permeado pelas TDIC, e embora os jogos digitais desenvolvidos especificamente para fins pedagógicos sejam os mais utilizados nas escolas, há um número crescente de trabalhos que indicam que os jogos de simulação, estratégia e outros, desenvolvidos não com objetivos pedagógicos, e utilizados pelos jovens com regularidade como forma de diversão, podem também oferecer contribuições para o ensino e aprendizagem se utilizados com objetivos pedagógicos claros, com critério e com mediação do professor. 
VIII Congresso Brasileiro de Informática na Educação (CBIE 2019)

Anais do XXV Workshop de Informática na Escola (WIE 2019)

Todavia, observa-se ainda certa resistência em relação ao uso desses tipos de jogos na escola, por questões culturais, estruturais, e relacionadas à uma formação de professores que os auxilie a compreender como podem abordar os conteúdos de forma produtiva por meio desses jogos. Assim, torna-se relevante conhecer práticas pedagógicas realizadas nessa perspectiva, a fim de apresentar possibilidades aos educadores, visando a replicação em realidades compatíveis. Com esse objetivo, este artigo descreve uma experiência de uso do jogo Minetest, para a abordagem de conteúdos Matemáticos como Medidas de Comprimento, com estudantes de $5^{\circ}$ ano do Ensino Fundamental, em uma escola pública municipal. A experiência descrita é parte dos resultados obtidos em um estudo de caso qualitativo e interpretativo que analisou como a escola tem trabalhado pedagogicamente com as TDIC (KAMINSKI, 2018).

O artigo segue assim organizado: a Seção 2 traz aspectos teóricos e trabalhos correlatos que fundamentam o uso dos jogos de simulação e estratégia como o Minetest em contextos escolares; na Seção 3 a metodologia adotada e os principais resultados obtidos são descritos, e na Seção 4 estão as conclusões e perspectivas do trabalho.

\section{Jogos em Práticas Pedagógicas}

Os jogos assumiram formatos variados passando desde brincadeiras ao ar livre, jogos analógicos e atualmente, incluem os digitais. Mesmo em diferentes formatos, apresentam, segundo Prensky (2012), as seguintes características principais: regras que orientam as ações, objetivos ou metas que motivam às ações, resultados que indicam respostas às ações, desafios que incentivam a continuar o jogo, a interação entre os jogadores e o enredo que indica o que o jogo representa (um conflito, uma história). Para Schwartz (2014), jogar é uma atividade inerente aos humanos, que faz parte do nosso desenvolvimento histórico e cultural, e que representa um sentido motivador individual para cada pessoa, que atribui ao ato de jogar um significado próprio, mas de modo geral, traz o engajamento, a diversão e os desafios como aspectos mais atrativos.

Os jogos digitais têm ganhado espaço na realidade cibercultural brasileira, mas quando se trata da sua utilização em ambientes escolares e em práticas pedagógicas percebe-se uma redução significativa. A pesquisa do Comitê Gestor da Internet no Brasil (2018) indicou que apenas 20\% dos docentes das escolas públicas, e $49 \%$ das escolas privadas, têm utilizado jogos em suas práticas pedagógicas.

Em relação aos tipos de jogos explorados na escola, Prensky (2012) destaca que os pedagógicos representam a maioria do que se utiliza, sendo ainda pouco empregados os jogos criados não especificamente para fins educacionais, mas que segundo o autor podem trazer contribuições importantes se abordados com critério e um bom direcionamento por parte do professor, em função das suas características e dos desafios propostos que costumam atrair significativamente a atenção dos estudantes. Essa preferência pela utilização dos jogos pedagógicos nas atividades escolares, em detrimento aos jogos não educacionais em si, pode ser consequência de aspectos socioculturais, como indicado por Alves e Torres (2018):

A utilização dos jogos digitais nos espaços de aprendizagem pode tornar mais lúdico e interativo o processo de ensinar e aprender. Entretanto, ainda existe resistência para essa utilização nos cenários escolares, por conta de os jogos serem, frequentemente, responsabilizados por atos hediondos ou comportamentos julgados como inadequados. Esse estigma tem implicado em 
VIII Congresso Brasileiro de Informática na Educação (CBIE 2019)

Anais do XXV Workshop de Informática na Escola (WIE 2019)

posturas reservadas, por pais e professores, em relação às práticas pedagógicas mediadas por estes artefatos (p. 51).

Apesar dessa resistência, alguns estudos corroborando com Prensky (2012), têm indicado um potencial importante desses jogos em contribuir com os processos de ensino e aprendizagem, não apenas pelo aspecto motivacional, mas também por favorecerem o desenvolvimento de habilidades importantes à formação.

A exemplo disso, Moran (2012) aponta que os jogos exigem que os alunos aprendam a conviver com regras e a buscar soluções, desafiando-os a utilizar todos os limites das suas potencialidades desenvolvendo disciplina, concentração, perseverança, flexibilidade e organização. Filatro e Cairo (2015) colocam que os jogos apresentam desafios e possibilitam a resolução de problemas, dado que empregam componentes que favorecem a aprendizagem. Kenski (2015) indica que jogos como SimCity, The Sims e Age of Empires são exemplos de jogos que podem ser explorados em contextos educacionais, onde um jogo de batalhas, por exemplo, pode ser utilizado para abordar conteúdos de História. Além disso, em jogos cooperativos trabalha-se a coletividade, a cooperação e os relacionamentos interpessoais. Segundo Victal et al. (2015) os jogos permitem o desenvolvimento de habilidades e atitudes como:

\begin{abstract}
Raciocínio Espacial; Destreza Manual; Resiliência; Concentração (Foco); Autonomia; Camaradagem; Representação Simbólica; Interesse pela Pesquisa; Trabalho Cooperativo; Divisão de Problemas; Capacidade Inovativa; Disciplina; Método para solução de problemas; Capacidade para tomada de decisão; Capacidade de Gerenciar Tempo; Definição de Estratégias; Interpretação de Cenários; Reconhecimento de Padrões; Capacidade crítica; Pensamento Sistêmico; Raciocínio Dedutivo; Interpretação de Textos; Auto Confiança; Capacidade Empreendedora; Memorização; Pensar sobre o próprio pensamento; Abstração (p. 449).
\end{abstract}

Sousa (2016) também destaca o potencial motivador e desafiador desses tipos de jogos, que ganham espaço em um contexto de educação criativa, que incentiva a autonomia e a tomada de decisões, e Alves e Torres (2018) salientam que os jogos podem promover a aprendizagem chamada de colateral na medida em que estimulam funções cognitivas necessárias ao desenvolvimento que incluem a organização, a experimentação, a memória, a iniciativa e a tomada de decisões, ao mesmo tempo em que possibilitam a abordagem, a discussão e o emprego dos conteúdos curriculares. Por essa razão, os jogos não propriamente criados para fins pedagógicos têm sido explorados no espaço escolar com objetivos educacionais.

Como exemplo dessas práticas pedagógicas podemos citar Ilha e Cruz (2006), que relatam o desenvolvimento de um projeto envolvendo o jogo SimCity por professores das disciplinas de Matemática, Geografia e Língua Portuguesa, com estudantes de Ensino Médio de uma escola técnica do Vale do Itajaí/SC. Os autores indicam que, segundo o relato dos professores, o jogo contribuiu com o avanço do conteúdo de forma significativa e interdisciplinar, apesar de algumas limitações estruturais, além de gerar grande engajamento dos alunos pelo próprio aprendizado.

Marques e Silva (2009) relatam uma experiência com alunos do $9^{\circ}$ ano de uma escola pública, onde desenvolveram um projeto de 5 aulas com o jogo SimCity, e destacam o potencial transversal e interdisciplinar do jogo ao abordar a construção e a administração de uma cidade com todos os elementos que a compõe, desenvolvendo a 
VIII Congresso Brasileiro de Informática na Educação (CBIE 2019)

Anais do XXV Workshop de Informática na Escola (WIE 2019)

habilidade de tomar decisões de maneira crítica. Os autores concluíram que o jogo ajudou os estudantes a ponderarem sobre questões do cotidiano, como de higiene, saneamento, colaboração e política, de forma mais reflexiva, pensando em atos e consequências das ações de cada cidadão.

Oliveira e Paixão (2016), utilizaram com discentes de $5^{\circ}$ e $6^{\circ}$ ano os seguintes jogos para abordagem de conteúdos da disciplina de História: Age of Empires, Spore e SimCity, e destacam que por meio dos jogos os aprendizes puderam perceber a relação entre as ações do presente e suas consequências para o futuro, e assimilar conceitos de política, história e decisões coletivas. Para esses autores, os jogos contribuíram para a compreensão mais significativa dos conceitos à medida que simularam a realidade.

Lorenzoni (2016) aponta que mais de mil escolas, em mais de quarenta países, utilizam o jogo Minecraft em diferentes disciplinas como História (análise de construções históricas antigas), Matemática (construção da réplica do prédio escolar), Química (combinação de elementos) e Geografia (estudo de diferentes biomas). Lopes (2016) destaca que há disponível uma versão educativa do Minecraft que permite ao professor a criação de portfólios de atividades, com sugestão de planos de aula e a possibilidade de ter até 40 alunos trabalhando colaborativamente em uma construção.

A literatura supracitada aponta que os elementos trazidos por esses jogos representam parte da realidade de forma simulada e permitem que o professor, de forma interdisciplinar, promova discussões, relações e análises acerca de muitos conteúdos, o que contribui para que o aprendiz perceba sua aplicação na realidade e atribua sentido ao que está aprendendo, além de possibilitar o desenvolvimento das habilidades cognitivas, sociais e emocionais pelo trabalho desafiador, colaborativo e cooperativo que possibilitam desenvolver. Todavia, como salientado já por Valente (1999), é preciso utilizá-los com critérios e mediação pedagógica para que o jogo não sirva apenas como instrumento de ludicidade, mas de ensino e aprendizagem. O estudante pode fazer uso de estratégias e conceitos equivocados ou mesmo corretos, mas sem consciência de que o avanço no jogo ocorreu por ter aplicado um conceito corretamente. Assim, o uso do jogo não garante a aprendizagem do conteúdo pedagógico, e o professor deve discutir com os alunos as situações problemas, propiciando que o aluno aprenda. A vantagem da utilização do jogo está no fato de o estudante jogar, aplicando de forma consciente algum conceito estudado, como estratégia de jogo.

Desse modo, assim como ocorre com o uso de qualquer outro recurso didático, o que vai definir se um jogo foi ou não produtivo para os processos de ensino e aprendizagem, é a abordagem que o professor faz dele com planejamento e objetivos bem definidos. Nesse sentido, Alves e Torres (2018) destacam a importância de os professores conhecerem os jogos e suas potencialidades para que o trabalho tenha os resultados esperados, e indicam que a ausência desse conhecimento, junto com uma infraestrutura precária têm dificultado a implementação de práticas pedagógicas com jogos digitais. É relevante, portanto, buscar estratégias para superar as barreiras estruturais, e culturais para o uso de jogos em práticas pedagógicas, visto que eles podem apresentar importantes contribuições aos processos educativos conforme $\mathrm{o}$ referencial apresentado.

A próxima seção apresenta como o jogo Minetest foi utilizado pedagogicamente com estudantes do $5^{\circ}$ ano do Ensino Fundamental para trabalhar Medidas de 
VIII Congresso Brasileiro de Informática na Educação (CBIE 2019)

Anais do XXV Workshop de Informática na Escola (WIE 2019)

Comprimento, sob a perspectiva de produção e desafios, mas sem desaperceber a relação entre o jogo e o conteúdo curricular, e traz os principais resultados obtidos.

\section{Métodos e Resultados}

Este relato faz parte de um estudo de caso maior, descrito em Kaminski (2018), que seguiu o protocolo para estudo de caso estabelecido por Yin (2015), e que foi realizado entre os anos de 2017 e 2018, na Escola Municipal Aloys João Mann, Cascavel/PR. Trata-se de uma escola de porte médio, que atende atualmente 332 alunos entre Educação Infantil e Ensino Fundamental, cuja comunidade é considerada de classe média baixa. Como parte das atividades desenvolvidas com todos os alunos em período regular de ensino estão as aulas de Informática Educacional, que ocorrem no Laboratório de Informática, com duração de 40 minutos, uma vez por semana para cada turma, e que são preparadas e ministradas por uma Instrutora de Informática e consideram os conteúdos curriculares e as TDIC como parte do conhecimento que deve ser abordado na escola, visando à formação integral dos sujeitos (científica, cognitiva, social e emocional).

Em função de ser uma escola pública, que utiliza somente software gratuitos e/ou livres, era preciso escolher um jogo que atendesse essa necessidade, a fim de evitar problemas com licenças como também indicado por Ilha e Cruz (2006), além de ser compatível com o hardware das máquinas multiterminais do laboratório, que utilizam o sistema operacional Linux. Após pesquisas, optou-se pelo jogo Minetest (AHOLA, 2010), um jogo de simulação (construção) gratuito, de código aberto e compatível com Linux, por meio do qual, conforme apontado por Prensky (2012), vários conteúdos podem ser explorados pela contextualização. Nele o jogador é colocado em um ambiente com uma paisagem feita por blocos. O objetivo é explorar o ambiente, coletar blocos, minerar, coletar recursos para sobreviver e construir seu mundo a partir da exploração. Todos os artefatos necessários à sobrevivência são construídos pelo jogador a partir da exploração dos blocos.

Minetest é muito semelhante ao Minecraft (PERSSON, 2009), sendo que a principal diferença entre eles é que o Minecraft é um software proprietário, enquanto o Minetest não gera custos com licenças e abre possibilidade para abordagem de vários conteúdos, como Medidas de Comprimento, Superfície, Simetria, além de outras disciplinas como Ciências, História, Geografia, assim como Lorenzoni (2016) e Lopes (2016) indicam ser possível no Minecraft. Assim, a Instrutora pesquisou formas de utilizar esse jogo no ambiente escolar e organizou a atividade proposta a partir das possibilidades indicadas na literatura. Essa ideia surgiu em função da Instrutora saber, por meio da comunicação com e entre seus alunos, que eles costumavam passar tempo utilizando jogos de construção fora do ambiente escolar.

A experiência ora descrita aconteceu durante essas aulas de Informática, abordando o conteúdo Medidas de Comprimento com o Minetest, com duas turmas de estudantes de $5^{\circ}$ ano, sendo uma turma composta por 25 alunos no período matutino e uma turma composta por 26 alunos no período vespertino. $\mathrm{O}$ objetivo era que os alunos pudessem utilizar o jogo para construir a réplica de um dos blocos que compõem o prédio da escola. Nessa proposta, os alunos trabalhariam com as medidas, com a ideia de escalas, com a criatividade, com os desafios intrínsecos à proposta do jogo, com 
VIII Congresso Brasileiro de Informática na Educação (CBIE 2019)

Anais do XXV Workshop de Informática na Escola (WIE 2019)

colaboração e cooperação por meio do trabalho em equipe e outros aspectos também mencionados nos trabalhos correlatos apresentados na Seção 2. Inicialmente foram programadas três aulas para o trabalho, as quais, para fins do estudo foram analisadas por meio da observação participante com registro dos resultados em diário de campo.

$\mathrm{Na}$ primeira aula a Instrutora apresentou a proposta de trabalho aos estudantes e explicou que seria necessário reproduzir dentro do jogo, o bloco da escola onde se encontra o Laboratório de Informática, e que seria utilizada a escala de um bloco para cada metro. Os alunos receberam a proposta da atividade com empolgação. A maioria dos estudantes conhecia o Minecraft e relacionaram os dois nomes. Algumas expressões dos estudantes são descritas na sequência, e para fins de codificação e preservação do anonimato, são indicadas pela letra A, seguidas da sequência numérica: A4:"Então teremos que saber a medida para poder ver quantos blocos vamos precisar!" A15: "Vixi! Como vamos saber as medidas?"

A Instrutora dividiu os discentes em grupos, e os organizou de modo que cada equipe ficou responsável por medir, com o auxílio de um metro, um dos espaços que compõem o bloco da escola indicado para o trabalho, registrando as medidas obtidas. Essa aula foi utilizada apenas para a medição dos espaços. As Figuras 1(a) e (b) ilustram momentos dos alunos trabalhando nas medições.

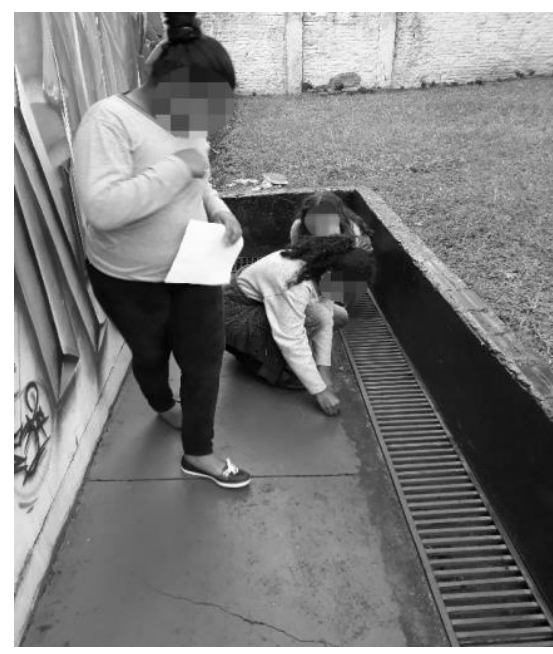

(a)

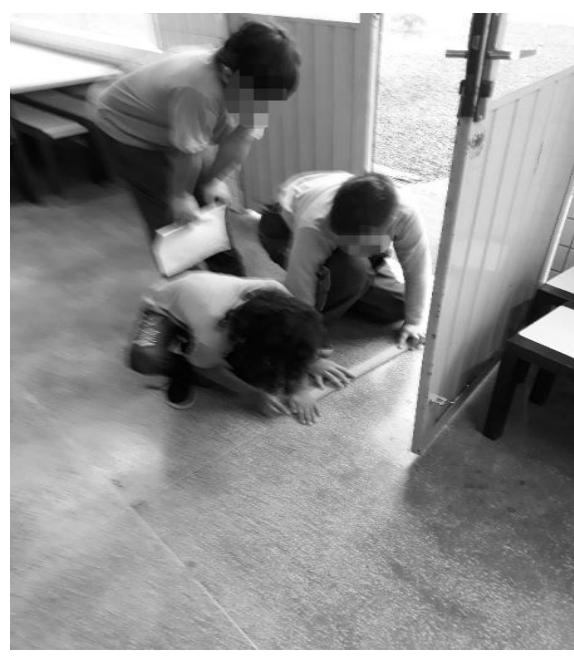

(b)

Figura 1. Estudantes trabalhando na verificação das medidas da escola Fonte: Dados da Pesquisa (2018).

Os estudantes tiveram dificuldades no momento das medições. Muitos não sabiam utilizar o instrumento, outros posicionavam de qualquer maneira gerando medidas equivocadas. O acompanhamento da Instrutora durante todo o processo foi imprescindível para garantir medidas corretas e para sanar as dúvidas que surgiram. Essa atividade prática foi bastante produtiva no sentido de possibilitar o trabalho com instrumentos de medida, contribuindo para a superação das dificuldades, a melhor compreensão do conteúdo e a aprendizagem. Ao final da aula, os dados obtidos por cada grupo foram compartilhados para que todos tivessem as medidas de todos os espaços que compõem o bloco que deveria ser construído no jogo. 
VIII Congresso Brasileiro de Informática na Educação (CBIE 2019)

Anais do XXV Workshop de Informática na Escola (WIE 2019)

$\mathrm{Na}$ segunda aula a Instrutora organizou os discentes em duplas, considerando as limitações dos equipamentos do laboratório, uma vez que não é possível trabalhar com o Minetest em multiterminais utilizando as três telas simultaneamente. $\mathrm{O}$ multiterminal permite o trabalho apenas em uma das telas com esse jogo. Assim, a Instrutora organizou duplas de modo que os alunos que não conheciam o jogo trabalhassem com os que já conheciam, visando à aprendizagem colaborativa. Essa organização necessitou dos 8 multiterminais disponíveis, do servidor, e de três notebooks emprestados da sala dos professores para o trabalho, além do notebook pessoal da Instrutora.

Com as duplas organizadas, a Instrutora distribuiu para cada dupla, um mapa por ela elaborado, do bloco a ser construído, com os resultados das medições compartilhadas para que começassem os trabalhos de construção. Alguns estudantes tiveram inicialmente dificuldades na manipulação do jogo, mas logo conseguiram fazer uso dos comandos necessários. Dúvidas começaram a surgir: A3: "Não temos um lugar plano."; A16: "A construção não pode ser em uma montanha!"; A21: "Não dá pra fazer aqui porque não é plano!". Surgiram discussões sobre os tipos de relevo e as transformações que o homem faz nas paisagens naturais, e os alunos concluíram: A12: "Vamos ter que procurar outro lugar ou fazer isso daqui ficar plano de qualquer jeito!". Após definirem um local adequado, iniciaram a construção. Durante o processo tiveram que procurar materiais adequados: A14: "A escola é feita de tijolo e não de madeira!"; A17: "Vamos ter que procurar rochas."

Os aprendizes também sentiram necessidade de se alimentar, se abrigar, dormir ou conseguir luz para os momentos em que anoitecia no jogo. Surgiram discussões sobre questões do tipo: Podemos trabalhar o tempo todo? Quais as limitações e necessidades do ser humano? O que acontece se não forem respeitadas?

O progresso da construção fica salvo no jogo de modo que os alunos podiam continuar do ponto onde pararam na aula seguinte. As duas aulas programadas para a construção não foram o suficiente tanto pela complexidade da atividade em si, quanto por problemas estruturais. As máquinas multiterminais em vários momentos apresentaram lentidão tornando o processo de construção no jogo mais demorado. Os discentes reclamaram bastante sobre isso, especialmente por que estavam focados no projeto e desejosos de completá-lo. Mais duas aulas, então, foram destinadas para o trabalho. Ainda assim, não foi possível concluir a construção de todo o bloco, de modo que para cada dupla, ficaram faltando várias partes para que projeto fosse finalizado.

A limitação das máquinas foi um problema bastante significativo, assim como apontado por Alves e Torres (2018), que levou à não conclusão do projeto. Acredita-se que seriam necessárias aproximadamente mais cinco aulas para concluir da maneira como foi proposto. Porém, muitas aulas sequenciais sobre o mesmo tema e software, em equipamentos que não correspondem às necessidades acabam gerando ansiedade e levam à perda do foco da atividade, não sendo produtivo frente aos objetivos propostos. A Figura 2 mostra partes do que foi construído pelos estudantes, sendo que a Figura 2(a) mostra a réplica do corredor do bloco que conduz à entrada do refeitório, 2(b) representa o refeitório, 2(c) a sala dos professores e a Figura 2(d) representa parte dos canteiros que compõem a horta da escola e pertencem ao bloco construído.

As habilidades e competências descritas em Victal et al. (2015) e citadas na Seção 2 foram identificadas, ainda que algumas em menor grau, na atividade 
VIII Congresso Brasileiro de Informática na Educação (CBIE 2019)

Anais do XXV Workshop de Informática na Escola (WIE 2019)

desenvolvida. Minetest, como outros jogos já citados como não desenvolvidos inicialmente para fins educacionais, também permitiu o exercício de trabalho colaborativo e, a exemplo de Oliveira e Paixão (2016), Minetest contribuiu à compreensão mais significativa dos conceitos, que ficaram mais concretos pelo jogo.

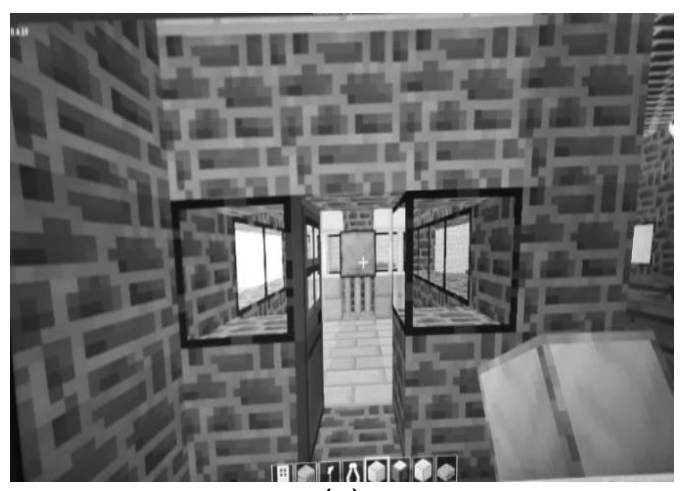

(a)

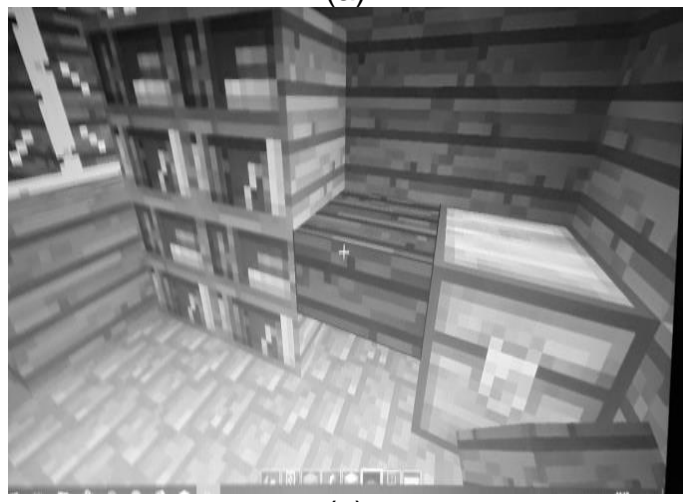

(c)

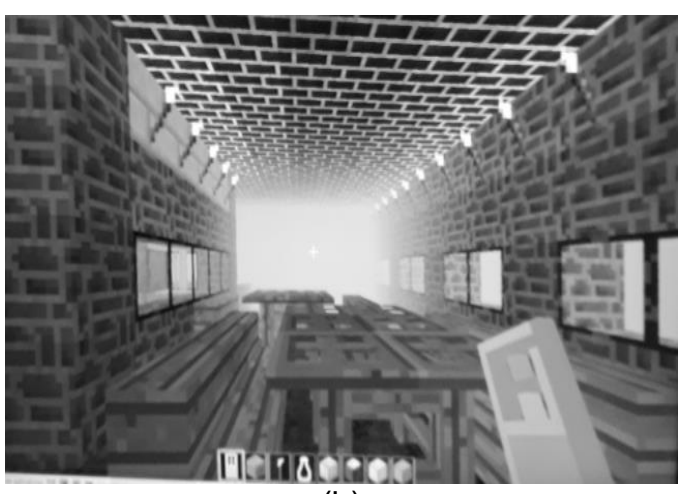

(b)

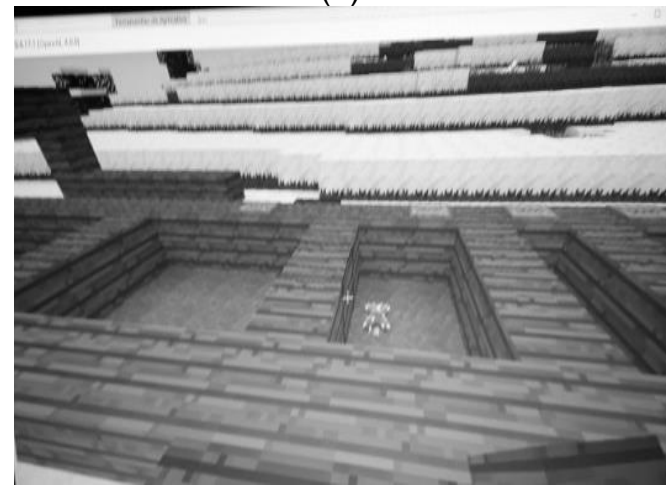

(d)

Figura 2. Construção dos alunos no Minetest

Fonte: Dados da Pesquisa gerados com o Minetest (2018).

Embora não tenha sido possível concluir, na totalidade, o objetivo inicial, a atividade foi válida pela riqueza das discussões interdisciplinares que gerou. Os alunos puderam trabalhar com medidas, escala, reconhecimento do espaço escolar, mapas, além de desenvolver a criatividade para decorar e compor os espaços, e aspectos sociais e emocionais pelo trabalho em equipe, em consonância com os resultados dos trabalhos correlatos da Seção 2, que também apontaram a dificuldade em termos de hardware, a exemplo de Ilha e Cruz (2006).

\section{Considerações Finais}

Este artigo apresentou uma proposta e reflexões do uso do Minetest no $5^{\circ}$ ano do Ensino Fundamental, que pode ser reproduzida e/ou adaptada a diferentes contextos. O trabalho possibilitou uma abordagem diferenciada do conteúdo, que promoveu o engajamento dos estudantes, que conseguiram atribuir um sentido às atividades propostas, desde o momento em que necessitaram utilizar o instrumento de medidas, até o momento em que estavam construindo algo planejado - o que representou um desafio -, e não uma construção arbitrária, atribuindo um significado diferente ao ato de jogar, pois fora da escola, utilizam o jogo de forma livre. 
VIII Congresso Brasileiro de Informática na Educação (CBIE 2019)

Anais do XXV Workshop de Informática na Escola (WIE 2019)

Apesar de a limitação estrutural não ter possibilitado a conclusão do projeto idealizado, foi possível perceber os benefícios da proposta em consonância com o indicado pela literatura pesquisada. Além do inegável engajamento, o desenvolvimento de aspectos cognitivos, sociais e emocionais permearam todas as aulas, visto que os alunos precisaram levantar hipóteses, enfrentar desafios, buscar soluções, trabalhar em equipe de forma colaborativa e cooperativa. O jogo também favoreceu a discussão de tópicos de outras disciplinas de modo que a atividade teve caráter interdisciplinar.

$\mathrm{Na}$ forma como o laboratório estava estruturado com multiterminais até o final da pesquisa, seria interessante uma adaptação da atividade, propondo projetos mais simples, que envolvam um tempo menor, considerando as limitações e visando a conclusão, na íntegra, da proposta. Para projetos mais complexos e trabalhos colaborativos, onde os discentes participam juntos na construção de um único projeto, como sugerido por alguns trabalhos correlatos citados na Seção 2, as máquinas multiterminais se tornam inviáveis, limitando o potencial de exploração desses jogos.

Após a conclusão da pesquisa, o laboratório da escola passou por uma reestruturação, de modo que atualmente conta com 27 máquinas individuais, ainda com Sistema Linux. Assim, novas abordagens do uso do jogo estão sendo planejadas a fim de avaliar se esta nova configuração é mais propícia ao trabalho com o software tanto em construções individuais quanto colaborativas. Também estão em planejamento a abordagem de outros conteúdos como Simetria e Área, e o uso de outros jogos de simulação que sejam livres.

O que se pretende com o uso dos jogos é trazer para o contexto educacional, artefatos que façam parte do cotidiano dos alunos e, mais do que isso, que possibilitem a exploração interdisciplinar dos conteúdos e, ainda que de forma simulada, contextualizada com a realidade onde o estudante possa experimentar, testar, conjecturar, avaliar resultados e tomar decisões. Para tanto, a mediação do professor desde a escolha do jogo, a elaboração da proposta - que deve primar por algo diferente do uso que o estudante faz do jogo fora da escola -, até avalição é primordial.

\section{Referências}

Ahola, P. (2010) “Minetest”. Disponível em: https://www.minetest.net/. Acesso em: 05 jun. 2019.

Alves, L. and Torres, V. (2018) "Jogos Digitais e Espaços de Aprendizagem: Desafios Socioculturais e Possibilidades Pedagógicas". In: Comitê Gestor da Internet no Brasil. TIC Educação Pesquisa sobre o Uso das Tecnologias de Informação e Comunicação nas Escolas Brasileiras. São Paulo: Núcleo de Informação e Coordenação do Ponto Br, p. 51-58. Disponível em: http://twixar.me/RlT1. Acesso em: 04 jun. 2019.

Comitê Gestor da Internet no Brasil - CGI (2018) "TIC EDUCAÇÃO 2017 - Pesquisa Sobre o Uso das Tecnologias de Informação e Comunicação nas Escolas Brasileiras". 438 p. Disponível em: https://bit.ly/2sq1xUH/. Acesso em: 05 jun. 2019.

Filatro, A. and Cairo, S. (2015), Produção de Conteúdos Educacionais: Design instrucional, tecnologia, gestão, educação e comunicação. São Paulo: Saraiva, 462 p. 
VIII Congresso Brasileiro de Informática na Educação (CBIE 2019)

Anais do XXV Workshop de Informática na Escola (WIE 2019)

Ilha, P. C. A. and Cruz, D. M. (2006) "Jogos eletrônicos na educação: uma pesquisa aplicada do uso do Sim City4 no ensino médio". In: Workshop de Informática na Escola, p. 240-246. Disponível em: http://twixar.me/Q1T1. Acesso em: 04 jun. 2019.

Kaminski, M. R. (2018), Análise das Práticas de Informática na Educação da Escola Municipal Aloys João Mann - Cascavel/PR. 254 f. Dissertação (Mestrado em Ensino) - Universidade Estadual do Oeste do Paraná, Foz do Iguaçu. Disponível em: http://tede.unioeste.br/handle/tede/4212. Acesso em 06 set. 2019.

Kenski, V. M. (2015), Design instrucional para cursos on-line. São Paulo: Senac, 379 p.

Lopes, M. (2016) "Versão educativa do Minecraft chega à sala de aula". Revista Porvir. Disponível em: http://twixar.me/61T1/. Acesso em: 06 jun. 2019.

Lorenzoni, M. (2016) "5 projetos com Minecraft para a sua sala de aula". A Rede Educa. Disponível em: http://www.arede.inf.br/3432-2/. Acesso em: 06 jun. 2019.

Marques, N. and Silva, B. (2009) "Potencialidades pedagógicas dos jogos electrónicos: um estudo descritivo com o Sim City”. In: Dias, P.; Osorio, A. and Ramos, A. (Org). O digital e o currículo. Braga: Centro de Competência da Universidade do Minho, p. 139-161.

Moran, J. M. (2012), A Educação que desejamos: Novos desafios e como chegar lá. 5 a ed. São Paulo: Papirus. 174 p.

Oliveira, M. S. and Paixão, L. A. D. (2016) "O jogo da História: Aprendizagens significativas e jogos eletrônicos numa escola municipal do interior da Bahia.” In: Alves, L. and Coutinho, I. D. J. (Org). Jogos Digitais e Aprendizagens: Fundamentos para uma prática baseada em evidências. Campinas: Papirus, p. 227-244.

Persson, M. (2009) “Minecraft”. Disponível em: https://minecraft.net/pt-br/. Acesso em: 07 jun. 2019.

Prensky, M. (2012), A aprendizagem baseada em jogos digitais. São Paulo: SENAC, $546 \mathrm{p}$.

Schwartz, G. (2014), Brinco, logo aprendo: educação, videogames e moralidades pósmodernas. São Paulo: Paulus, 343 p.

Sousa, C. A. B. de. (2016) "O jogo em foco: uma discussão sobre os games e a aprendizagem". In: Raabe, A. L. A.; Gomes, A. S.; Bittencourt, I. I. and Pontual, T. Educação criativa: multiplicando experiências para a aprendizagem, 472 p. Série professor criativo: construindo cenários de aprendizagem - v. 4 (e-book). p. 301-347.

Valente, J. A. (1999) "Informática na educação no Brasil: Análise e Contextualização Histórica". In: Valente, J. A. (Org.). O computador na sociedade do conhecimento. Campinas: UNICAMP/NIED, p. 01-13.

Victal, E. R. D. N.; Pereira Junior, H. A; Rios, P. T. G. and Crediné, S. D. M. (2015) "Aprendendo sobre o uso de Jogos Digitais na Educação". In: Workshop de Informática na Escola, p. 444-453. Disponível em: http://twixar.me/gSB1. Acesso em: 04 jun. 2019.

Yin, R. K. (2015), Estudo de caso: planejamento e métodos. $5^{\text {a }}$ ed. Porto Alegre: Bookman, 290 p. 